\title{
Highly efficient uptake of neptunium from acidic feeds using two solid phase extraction resins containing diglycolamide-functionalized calix[4]arene ligands
}

\author{
Rajesh B. Gujar ${ }^{a}$, Prasanta K. Mohapatra ${ }^{a, *}$, Mudassir Iqbal ${ }^{b}$, Jurriaan Huskens ${ }^{b}$, \\ Willem Verboom ${ }^{\mathrm{b}, *}$ \\ ${ }^{a}$ Radiochemistry Division, Bhabha Atomic Research Centre, Mumbai-400 085, India \\ ${ }^{\mathrm{b}}$ Laboratory of Molecular Nanofabrication, MESA+ Institute for Nanotechnology, University of Twente, P. 0. Box 217, 7500 AE Enschede, The Netherlands
}

\section{A R T I C L E I N F O}

\section{Article history:}

Received 20 December 2020

Revised 25 February 2021

Accepted 27 February 2021

Available online 4 March 2021

\section{Keywords:}

Neptunium(IV)

Solid phase extraction

Radioactive waste

Diglycolamide

Calix[4]arene

\begin{abstract}
A B S T R A C T
Two solid phase extraction resins (SPER) were prepared by impregnating solutions of two diglycolamidefunctionalized calix[4]arenes in $10 \%$ isodecanol in $n$-dodecane into Chromosorb W, as the stationary phase. While SPER-I contained n-propyl functionalized calix[4]arene, SPER-II contained the calix[4]arene with isopentyl groups at the carboxamide nitrogen atoms. The SPERs were characterized by SEM, TGA, FTIR, etc. and were used for the batch uptake of neptunium(IV) from nitric acid feed solutions. While the uptake of $\mathrm{Np}(\mathrm{IV})$ was extremely high with SPER-I $\left(K_{\mathrm{d}}: 47,544\right.$ at $3 \mathrm{M}$ nitric acid, ca. $8 \%$ extractant loading), SPER-II displayed a significantly lower extraction efficiency ( $K_{\mathrm{d}}: 13,724$ under identical conditions) as indicated by the batch uptake studies. Sorption isotherm studies were carried out which indicated good fitting to the Langmuir model suggesting uptake conforming to monolayer sorption. Fitting to the D-R isotherm model conformed to a chemisorption model. Column studies were also carried out and the elution profiles, obtained with solutions of oxalic acid and nitric acid indicated very sharp peaks suggesting that the column can be used for the separation of $\mathrm{Np}$ (IV) from acidic radioactive feeds.
\end{abstract}

(c) 2021 Elsevier B.V. All rights reserved.

\section{Introduction}

Neptunium is one of the most important actinide elements relevant in the nuclear fuel cycle as it is produced in large quantities during reactor operations wherein the nuclear fuel is bombarded with thermal neutrons. Due to its long half-life $\left(\mathrm{t}_{1 / 2}: 2.1 \times 10^{6} \mathrm{y}\right)$, ${ }^{237} \mathrm{~Np}$, the most abundant isotope of neptunium found in the spent fuel, also considered as one of the major constituents of the highlevel liquid waste (HLLW) emanating from spent fuel reprocessing and hence, requires special attention [1]. The separation of minor actinides such as Np, Am and Cm from the HLLW [2-4] followed by their transmutation in high flux reactors or accelerator driven sub-critical systems (ADSS) is one of the major strategies for radioactive waste management [5]. Neptunium is unique due to its coexistence in a number of oxidation states in acidic feeds depending on the redox conditions [6]. Also, $\mathrm{Np}(\mathrm{V})$ can easily disproportionate depending on the feed acid conditions [7]. While $\mathrm{Np}$ (IV) can be conveniently extracted using TBP (tri-n-butyl phosphate),

\footnotetext{
* Corresponding authors.

E-mail addresses: mpatra@barc.gov.in (P.K. Mohapatra), w.verboom@utwente.nl (W. Verboom).
}

the commonly used extractant in the back end of the nuclear fuel cycle, it cannot co-extract other minor actinide ions such as Am(III) and $\mathrm{Cm}$ (III) due to their lower ionic potential. In this context, other extractants tailor made for the actinide partitioning can become handy. Diglycolamides (DGA) are a class of extractants with very high efficiency for the extraction of trivalent actinides [8-10]. However, there are only a handful of reports on the extraction of $\mathrm{Np}$ from acidic feeds using DGAs [11,12].

Recently, we developed multiple-DGA ligands where the DGA moieties are appended to macrocyclic scaffolds such as the calix[4]arenes [13]. These extractants have shown very high extraction efficiency towards the trivalent actinides but their affinity towards $\mathrm{Np}(\mathrm{IV})$ extraction was mostly unexplored [14]. Recently, we have reported the solvent extraction of Np using several DGAfunctionalized calix[4]arenes and the results were quite promising [15].

The solvent extraction processes require large solvent inventory and generate very high volumes of secondary wastes. While proposing solvent extraction based separation processes involving exotic ligands such as the DGA-functionalized calix[4]arenes, the cost can be very high in spite of the use of very low extractant concentrations [14]. On the other hand, solid phase extraction 


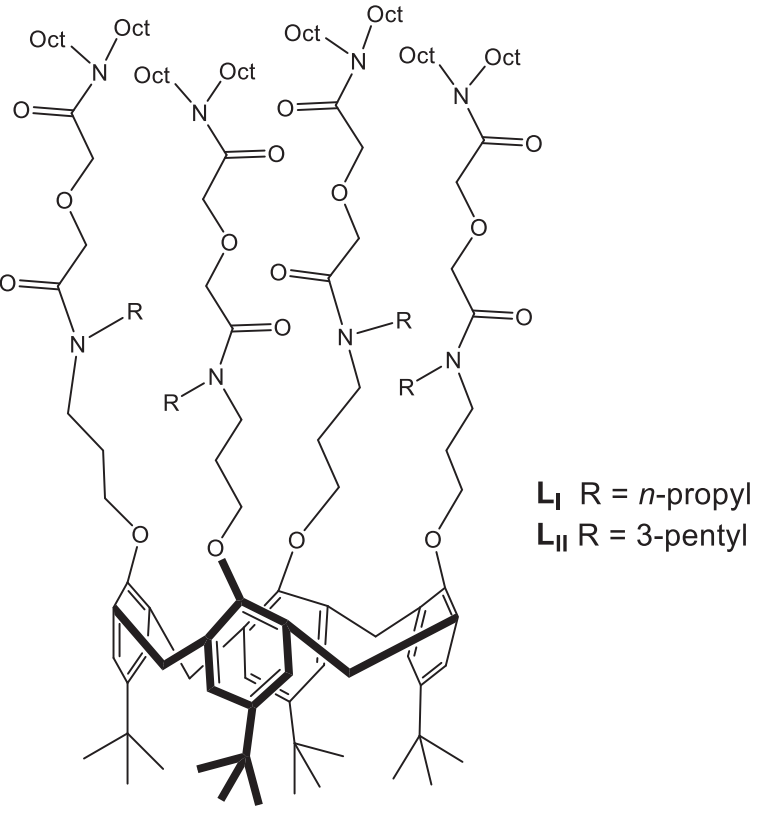

Fig. 1. Structure of the C4DGA ligands $\mathbf{L}_{\mathbf{I}}$ and $\mathbf{L}_{\mathbf{I I}}$.

methods where such ligands can be impregnated into a porous support material such as Chromosorb W (dimethyl dichlorosilane treated acid washed celite diatomaceous silica) can be quite interesting. It is now well known that such solid phase extraction resins can distinctly bring down the cost of the separation process and can be operated in the column mode, thereby giving the advantages of both solvent extraction as well as ion exchange methods [16-19].

The present paper deals with the preparation of two novel solid phase extraction resin (SPER) materials termed as SPER-I and SPER-II containing two DGA-functionalized calix[4]arene ligands (C4DGA), termed as $\mathbf{L}_{\mathbf{I}}$ and $\mathbf{L}_{\mathbf{I I}}$ (Fig. 1), impregnated into the pores of the solid support material, Chromosorb $\mathrm{W}$ and subsequent evaluation of $\mathrm{Np}$ (IV) uptake from nitric acid feeds by batch as well as column studies. The results were compared with other analogous resin materials reported in the literature for $\mathrm{Np}$ (IV) uptake from acidic feeds. To our mind, this is the first ever report on the solid phase extraction of neptunium using impregnated C4DGA ligands. As the C4DGA ligands are considered highly efficient for actinide ion extraction [13-15], the resins are considered to be highly efficient for $\mathrm{Np}(\mathrm{IV})$ ion.

\section{Experimental}

\subsection{Chemicals}

The C4DGA ligands $\mathbf{L}_{\mathbf{I}}$ and $\mathbf{L}_{\mathbf{I I}}$ (Fig. 1) were synthesized following a reported procedure [13] and were characterized by standard techniques such as ${ }^{1} \mathrm{H}$ NMR, HPLC, and HR-MS. ChromosorbW (mesh size 60-80) was procured from John Manville, USA and was given two cycles of alternate washings with distilled water and ethanol to get rid of the inorganic and organic impurities, respectively, followed by drying in an oven at $70{ }^{\circ} \mathrm{C}$ to remove the solvents. 2-Thenoyltrifluoroacetone (TTA) and sulphamic acid (both $>99 \%$ pure and procured from Sigma-Aldrich) were used as received. Dilute nitric acid solutions were prepared from Suprapur nitric acid (Merck) and MilliQ water (Millipore, USA) and were standardized volumetrically prior to use. All other chemicals were of AR grade.

\subsection{Radiotracers}

${ }^{241} \mathrm{Am}$, Pu (mainly ${ }^{239} \mathrm{Pu}$ ), and ${ }^{233} \mathrm{U}$ were used from the laboratory stock solutions, while ${ }^{152,154} \mathrm{Eu}$ and ${ }^{137} \mathrm{Cs}$ were obtained from the Board of Radiation and Isotope Technology (BRIT), Mumbai and were used after checking their radiochemical purities by alpha- / gamma-ray spectrometry as the case required. Carrier free ${ }^{239} \mathrm{~Np}$ was prepared by neutron activation of uranyl nitrate hexahydrate (ca. $2 \mathrm{mg}$ ) in the Dhruva reactor at BARC using a thermal neutron flux of $8 \times 10^{13} \mathrm{n} \cdot \mathrm{cm}^{-2} \cdot \mathrm{s}^{-1}$. The thus produced ${ }^{239} \mathrm{~Np}$ radiotracer was purified using a previously reported method [20] where the irradiated uranium salt was dissolved in dilute nitric acid $(0.5 \mathrm{M})$ and processed to get $\mathrm{Np}$ in the +4 oxidation state (by the addition of a few drops of $5.0 \times 10^{-2} \mathrm{M}$ ferrous sulphamate and $0.5 \mathrm{M}$ hydroxylamine hydrochloride) followed by TTA extraction (0.5 M TTA in xylene). The aqueous solution was considered to have quantitatively converted $\mathrm{Np}$ to its +4 oxidation state. The organic phase, containing the $\mathrm{Np}(\mathrm{IV})$-TTA extract, was carefully separated and the extracted $\mathrm{Np}(\mathrm{IV})$ was stripped using $7.5 \mathrm{M} \mathrm{HNO}_{3}$. The stripped aqueous phase containing ${ }^{239} \mathrm{~Np}$ was washed twice with xylene to remove small quantities of TTA dissolved in the aqueous phase and was subsequently used as the $\mathrm{Np}$ (IV) stock $(0.7$ milli Curie in $1 \mathrm{~mL}$ ). The batch uptake and column studies were carried out using this $\mathrm{Np}(\mathrm{IV})$ stock solution whose oxidation state was checked every week by TTA extraction studies [20].

\subsection{Radiometric assay}

${ }^{241} \mathrm{Am},{ }^{239} \mathrm{~Np},{ }^{152,154} \mathrm{Eu}$, and ${ }^{137} \mathrm{Cs}$ were assayed radiometrically for their emitting gamma rays using a well type $\mathrm{NaI}(\mathrm{Tl})$ scintillation counter (Para Electronics) interphased with a multichannel analyzer (ECIL, India). The alpha emitting radionuclides, viz. ${ }^{233} \mathrm{U}$ and ${ }^{239} \mathrm{Pu}$, were assayed by a liquid scintillation counter (Hidex, Finland) employing a toluene-based extractive scintillator cocktail containing 20\% D2EHPA (di-2-ethylhexyl phosphoric acid) to take care of quenching due to nitric acid. In view of the short half-life of ${ }^{239} \mathrm{~Np}(2.3 \mathrm{~d})$, decay correction was done for the gamma ray counts obtained. In cases where very low count rates were obtained, the counting was done for a longer time in order to discount the counting statistics error.

\subsection{Preparation of the SPE resins}

SPER-I and SPER-II, which contained $\mathbf{L}_{\mathbf{I}}$ and $\mathbf{L}_{\mathbf{I I}}$, respectively, were prepared following a reported method [21]. About $160 \mathrm{mg}$ of the ligands were taken along with a weighed quantity of the diluent mixture ( $10 \%$ isodecanol $+90 \% n$-dodecane) to make a total of $500 \mathrm{mg}$ of the solvent (ligand + diluents). The entire content of the solvents was added to two separate stoppered Erlenmeyer flasks, each containing a slurry made from ca. $1.5 \mathrm{~g}$ of Chromosorb $\mathrm{W}$ in $20 \mathrm{~mL}$ acetone. The mixture was agitated at ambient temperature for about $24 \mathrm{~h}$, whereupon the solvent was removed carefully by flushing nitrogen gas with gentle stirring. The resin materials with $>99 \%$ of the solvent evaporated were dried in a vacuum desiccator to constant weight to yield free flowing materials for the subsequent studies. From the difference between the final product and the Chromosorb $\mathrm{W}$ taken, the extractant loading on the solid support was roughly estimated as ca. $8 \%(w / w)$ for both the resins.

\subsection{Characterization of the SPE resins}

The resins, SPER-I and SPER-II, were characterized prior to their evaluation for $\mathrm{Np}$ (IV) uptake and these studies comprised of ligand loading and decomposition patterns by thermogravimetry (TGA), surface morphology by SEM (scanning electron microscope) and presence of the extractants inside the resin pores by FTIR (Fourier 
Transform Infrared) spectroscopy. The TGA studies were carried out using a NetzschThermobalance (Model: STA 409 PC Luxx) at a heating rate of $10{ }^{\circ} \mathrm{C}$ per minute in air atmosphere up to $800^{\circ} \mathrm{C}$. The combustion of the extractants present in the SPER pores resulted in changes seen in the graphs of mass loss vs temperature. The surface morphology of the SPE materials was analyzed by recording scanning electron micrograph (SEM) pictures using a Stereoscan 100 Cambridge model operating at 15/25 kV with a magnification of $3000 \mathrm{x}$ at a working distance of $15 \mathrm{~mm}$ at a tilt angle of $45^{\circ}$ after giving a $15 \mathrm{~nm}$ coating of gold using a Balzer's coating unit (model: CEA 30). Finally, the presence of the extractants inside the resin pores was characterized by FTIR recorded on a Bruker Alpha II ATR-FTIR spectrometer.

\subsection{Batch uptake studies}

The Np(IV) uptake by the SPERs was done by both batch as well as column mode operations. The batch uptake studies were carried out by contacting ca. $10-15 \mathrm{mg}$ of the SPERs, weighed accurately in plastic vials ( $10 \mathrm{~mL}$ capacity), to which $1 \mathrm{~mL}$ of the dilute nitric acid solution containing the radiotracer (ca. 900 - $1000 \mathrm{dps}$ ) was added. The batch uptake studies were carried out in a thermostated water bath at $25 \pm 0.1^{\circ} \mathrm{C}$ where the tubes were rotated vertically at a speed of $20 \mathrm{rpms}$ for about $1 \mathrm{~h}$, while ensuring that the tubes were always dipped inside the bath. The tubes were subsequently centrifuged and $100 \mu \mathrm{L}$ aqueous solution aliquots were removed for subsequent radiometric assay as mentioned above. The weight distribution coefficient $\left(K_{d}\right)$ values of the metal ions were calculated using the following equation:

$K_{d}=\left[\frac{\left(C_{o}-C\right)}{C}\right] \cdot \frac{V}{W}(\mathrm{~mL} / \mathrm{g})$

where $C_{o}$ and $C$ are the concentrations of metal ions expressed in terms of counts per unit time per unit volume before and after equilibration, respectively, and $V$ and $W$ represent the volume of the aqueous phase used (in $\mathrm{mL}$ ) and the weight of the resin (in g), respectively. All batch uptake experiments were carried out in triplicate and the accepted data were found to be within the relative standard deviation of $5 \%$. The concentrations of ${ }^{239} \mathrm{~Np},{ }^{241} \mathrm{Am}$ and $\mathrm{Pu}$ used in the present study were ca. $10^{-12} \mathrm{M}, 10^{-7} \mathrm{M}$ and $10^{-6} \mathrm{M}$, respectively, while those of ${ }^{137} \mathrm{Cs},{ }^{152,154} \mathrm{Eu}$ and ${ }^{233} \mathrm{U}$ were ca. $10^{-5} \mathrm{M}$.

The sorption isotherm studies were carried out by equilibrating the feed solutions containing varying concentrations of Th (in the range of $300 \mathrm{mg} / \mathrm{L}$ to $1000 \mathrm{mg} / \mathrm{L}$ ) but spiked with ${ }^{239} \mathrm{~Np}$ radiotracer. The counts in the aqueous phase were estimated from radiometric assay of ${ }^{239} \mathrm{~Np}$ which gives an idea about the $\mathrm{C}_{\mathrm{e}}$ (equilibrium concentration of the metal ion). The saturation batch uptake capacity was determined by equilibrating $20 \mathrm{mg}$ resin in a tube containing $1 \mathrm{~mL}$ of Th $(1 \mathrm{~g} / \mathrm{L})$ solution in $3 \mathrm{M} \mathrm{HNO}_{3}$ spiked with ${ }^{239} \mathrm{~Np}$ (ca. $1500 \mathrm{~Bq}$ ). Th(IV) was estimated by UV-visible spectrophotometry using Arsenazo III as the chromogenic agent as mentioned in a previous report [22]. As seen during our column studies, Th(IV) was a reasonably good surrogate of $\mathrm{Np}(\mathrm{IV})$ and hence, justifies its use in these studies as well.

\subsection{Column studies}

The column studies using the two SPERs were carried out using two glass columns (dimension: $20 \mathrm{~cm}$ (length) $\times 0.4 \mathrm{~cm}$ (dia)) fitted with bulbs of $10 \mathrm{~mL}$ capacity at the top and frits and stop cocks at the bottom. The columns were packed using a standard method where a known weight of the SPERs (ca. $500 \mathrm{mg}$ ) was added to the aqueous phase to yield slurries of solutions, which were subsequently poured into the column through the bulbs at the top of the column. Utmost care was taken to eliminate any air bubble in
Table 1

Various parameters for the column studies using the SPER-I and SPER-II resins.

\begin{tabular}{lll}
\hline Parameter & SPER-I (n-propyl) & SPER-II (isopentyl) \\
\hline Resin weight & $0.501 \mathrm{~g}$ & $0.505 \mathrm{~g}$ \\
Bed height & $12.1 \mathrm{~cm}$ & $12.3 \mathrm{~cm}$ \\
Bed volume & $2.5 \mathrm{~cm}^{3}$ & $2.6 \mathrm{~cm}^{3}$ \\
Bed density & $0.022 \mathrm{~g} / \mathrm{cm}^{3}$ & $0.022 \mathrm{~g} / \mathrm{cm}^{3}$ \\
Flow rate & $0.05 \mathrm{~mL}$ per minute & $0.05 \mathrm{~mL} \mathrm{per} \mathrm{minute}$ \\
\hline
\end{tabular}

the columns which could otherwise affect the flow rates. The column parameters are listed in Table 1.

The column studies included loading, washing and elution, each with a given aqueous solution as per the uptake and stripping characteristics of the metal ion standardized from the batch studies. Prior to loading the $\mathrm{Np}$ (IV)-containing feed solution, the columns were washed with an aqueous phase (ca. $10 \mathrm{~mL}$ ) containing the same concentration of nitric acid as in the feed, but sans the radiotracer. As the ${ }^{239} \mathrm{~Np}$ tracer is carrier free, it was decided to add thorium nitrate carrier as surrogate for the tetravalent neptunium. After conditioning of the column, the feed solution, containing $1 \mathrm{~g} / \mathrm{L}$ Th-nitrate solution spiked with the ${ }^{239} \mathrm{~Np}$ tracer (ca. $1000 \mathrm{~Bq}$ in $1 \mathrm{~mL}$ of the feed) was passed through the column and the effluent which came out of the column was counted to get the breakthrough profiles. In view of the short half-life of ${ }^{239} \mathrm{~Np}$, decay correction was done after the counting of all fractions was completed.

All column operations were carried out at ambient temperature $\left(24 \pm 1^{\circ} \mathrm{C}\right)$ and the column operations were carried out at a near constant flow rate of $0.05 \mathrm{~mL} / \mathrm{min}$. When not in use, the column flow rates were stopped using stop cocks and the bulbs were sealed with Para film. The solutions coming out of the columns were assayed radiometrically for the ${ }^{239} \mathrm{~Np}$ tracer presence as mentioned above for which decay correction was done. The elution of the loaded metal ions was done using a strip solution containing a mixture of $0.5 \mathrm{M}$ oxalic acid and $0.5 \mathrm{M}$ nitric acid. The uptake / breakthrough and the elution profiles were plotted as a function of volume of feed/eluent passed through the column to obtain the breakthrough / elution curves.

\section{Results and discussion}

\subsection{Characterization of the SPE resins}

The SPERs containing the extractants $\mathbf{L}_{\mathbf{I}}$ and $\mathbf{L}_{\mathbf{I I}}$ in the pores of the solid support, i.e., Chromosorb $\mathrm{W}$ were characterized prior to use for the uptake of metal ions. As mentioned above, the weight difference between resins indicated ca. 8\% extractant loading. This was further confirmed by thermogravimetric analysis (Fig. 2) for obtaining information about any water uptake, decomposition of the extractant, etc. As shown in Fig. 2, the weight loss in the temperature range of $100-120{ }^{\circ} \mathrm{C}$ was negligible (almost nil for SPER-I and $<1 \%$ for SPER-II), suggesting minimal moisture absorption by the resins. Also, it is clear that the resins were thermally stable up to $180-200{ }^{\circ} \mathrm{C}$ beyond which slow decomposition occurred. The final weights of the resins were close to $92 \%$, which remained constant up to $800{ }^{\circ} \mathrm{C}$. The TGA data proved about $8 \%$ loading of the ligands for both the resins and while the ligands were decomposed in the first step, the second step indicated complete removal of the oxide impurities.

The extractant loading was further confirmed by FTIR spectroscopic analysis (Fig. 3). The $>C=0$ stretching frequency at ca. 1600 $\mathrm{cm}^{-1}$ is clearly seen in the FTIR spectra of both the resins, indicating the presence of the extractants inside the resin pores. 

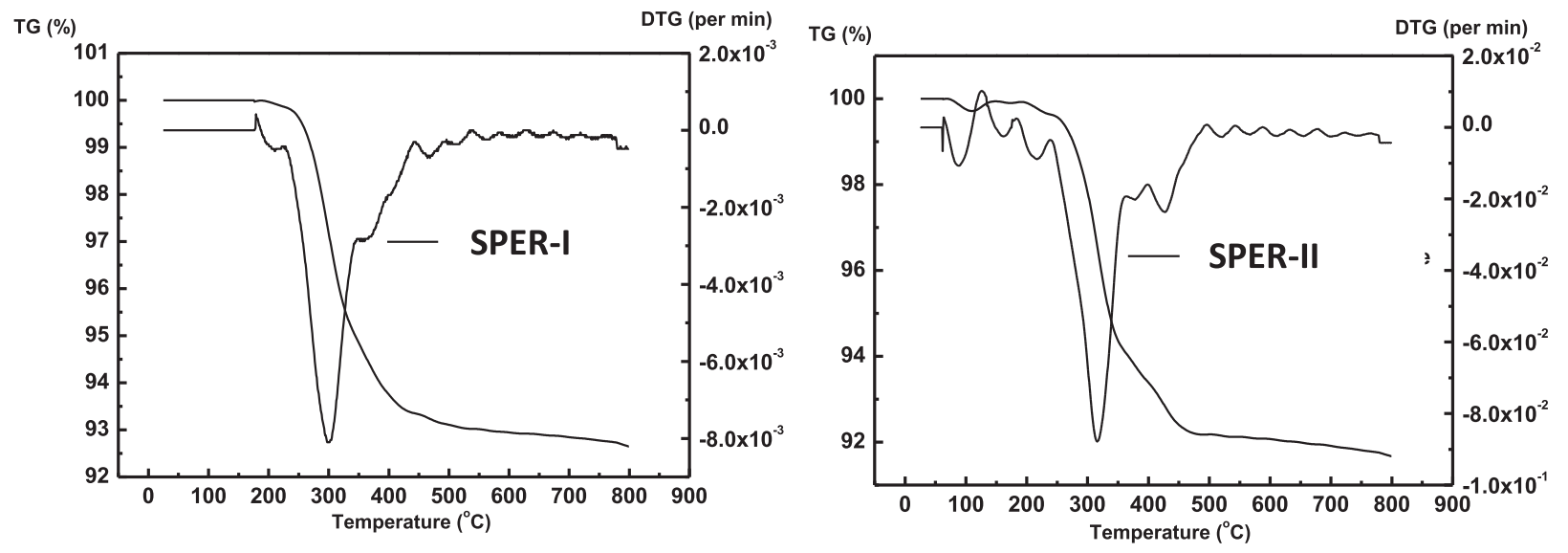

Fig. 2. Thermogravimetric analysis of SPER-I and SPER-II resins in air at $10{ }^{\circ} \mathrm{C}$ per minute as the heating rate.

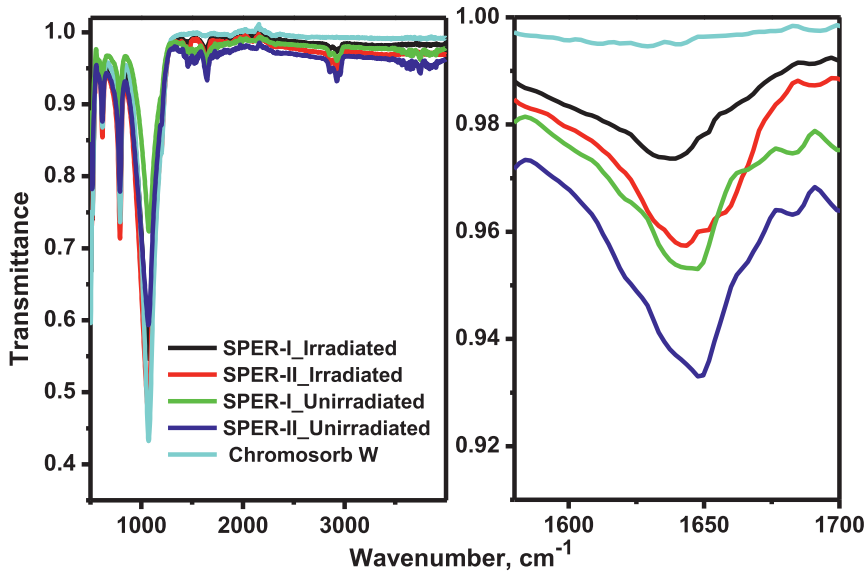

Fig. 3. FTIR spectra of pristine and irradiated SPER-I and SPER-II.

The SEM pictures for both the SPERs were obtained with varying magnifications and are presented in Fig. 4. The SEM pictures show porous honeycomb like structures in both the resins suggesting that the extractants are trapped inside the porous structures which can also lead to fast uptake kinetics, which is a key factor in developing the resin materials.

\subsection{Batch uptake studies}

The batch uptake of $\mathrm{Np}$ (IV) was studied from $3 \mathrm{M} \mathrm{HNO}_{3}$ (considered close to the acidity of the HLLW) using both SPER-I as well as SPER-II. For comparison purposes, the uptake studies were also carried out using pristine Chromosorb W (without any extractant). While no uptake of $\mathrm{Np}(\mathrm{IV})$ ion was seen with pristine Chromosorb $\mathrm{W}\left(K_{\mathrm{d}}<0.1\right)$, very large $K_{\mathrm{d}}$ values $\left(>10^{4}\right)$ were obtained with both SPER-I as well as SPER-II, the former yielding 3-4 times higher $K_{\mathrm{d}}$ values, hence, being one of the most efficient SPERs for $\mathrm{Np}$ (IV) uptake from nitric acid feeds. As mentioned in a separate section below, other actinide ions such as $\mathrm{Am}^{3+}$ and $\mathrm{Pu}^{4+}$, and $\mathrm{UO}_{2}{ }^{2+}$ to a much lesser extent, were also extracted by the resins suggesting that the resins can be used for the separation of actinide ions from acidic radioactive waste solutions. Table 2 lists the uptake data for $\mathrm{Np}(\mathrm{IV})$ with the two SPERs along with other analogous resins reported in the literature [23-27]. As almost no data are available of DGA-based resins such as TODGA for the uptake of $\mathrm{Np}$ (IV) ions, a comparison is made with $\mathrm{Th}(\mathrm{IV})$ and $\mathrm{Pu}(\mathrm{IV})$ data. All these indicate a superior uptake efficiency of the present set of resins. Also, the efficiency of an Aliquat 336-loaded SPER, which was used previ- ously for the uptake of $\mathrm{Np}$ (IV) from acidic feeds, was comparatively poor with about two orders lower $K_{\mathrm{d}}$ values.

\subsection{Metal ion uptake kinetics}

For effective application of the SPERs for the extraction of actinide ions such as $\mathrm{Np}(\mathrm{IV})$ from radioactive feeds, one of the key factors is the uptake kinetics. It is important to mention here that faster uptake kinetics can lead to better column performance of the SPER and hence, a suitable application can be made. The kinetics of the uptake of $\mathrm{Np}(\mathrm{IV})$ ion from $3 \mathrm{M} \mathrm{HNO}_{3}$ as the aqueous feed (spiked with ${ }^{239} \mathrm{~Np}$ radiotracer) was studied by measuring the $K_{\mathrm{d}}$ values at different time intervals.

The data on the kinetics of the uptake of $\mathrm{Np}$ (IV) from $3 \mathrm{M} \mathrm{HNO}_{3}$ using SPER-I and SPER-II, carried out in batch mode, are plotted as a function of the equilibration time in Fig. 5. Though fast uptake kinetics was expected (vide supra), ca. 1 hour was needed to attain the equilibrium $K_{\mathrm{d}}$ values for both the resins. Though solvent extraction studies indicated a much faster attainment of the extraction equilibrium [16], probably due to easier reorientation of the DGA arms in the diluent medium, the SPERs containing the calix[4]arene extractants are difficult to orient the DGA arms in view of the absence or presence of very little diluent leading to relatively slow uptake kinetics. Therefore, all subsequent batch uptake studies were carried out with 2 hours of equilibration time.

\subsection{Effect of the aqueous feed acidity}

Most of the radioactive wastes contain nitric acid as the medium. In view of this, it was pertinent to carry out uptake studies on $\mathrm{Np}(\mathrm{IV})$ using SPER-I and SPER-II at varying aqueous phase nitric acid concentrations. The extraction of $\mathrm{Np}(\mathrm{IV})$ using DGA ligands (L) such as TODGA and multiple DGA-containing ligands such as C4DGA from nitric acid feeds reportedly follow a solvation mechanism as per the following equation as given before [28]:

$\mathrm{Np}^{4+}{ }_{\mathrm{aq}}+\mathrm{nL}_{\text {org }}+4 \mathrm{NO}_{3 \mathrm{aq}}-\mathrm{Np}^{-}\left(\mathrm{NO}_{3}\right)_{4} \bullet \mathrm{nL}_{\text {org }}$

where the subscripts 'aq' and 'org' refer to the species present in the aqueous and the organic phases, respectively, and $n$ is close to 3 for TODGA (reported for tetravalent ions [28]), while it is close to 1 for a C4DGA extractant [15]. On the other hand, when the ligand is part of the SPER, it can be given by the following general equation:

$\mathrm{Np}^{4+}{ }_{\mathrm{aq}}+\mathrm{L}_{\mathrm{R}}+4 \mathrm{NO}_{3}{ }_{\mathrm{aq}}^{-}=\mathrm{Np}\left(\mathrm{NO}_{3}\right)_{4} \cdot \mathrm{L}_{\mathrm{R}}$

where the subscript ' $R$ ' represents species in the resin phase. Both the above equations indicate that the extraction of $\mathrm{Np}(\mathrm{IV})$ ion 

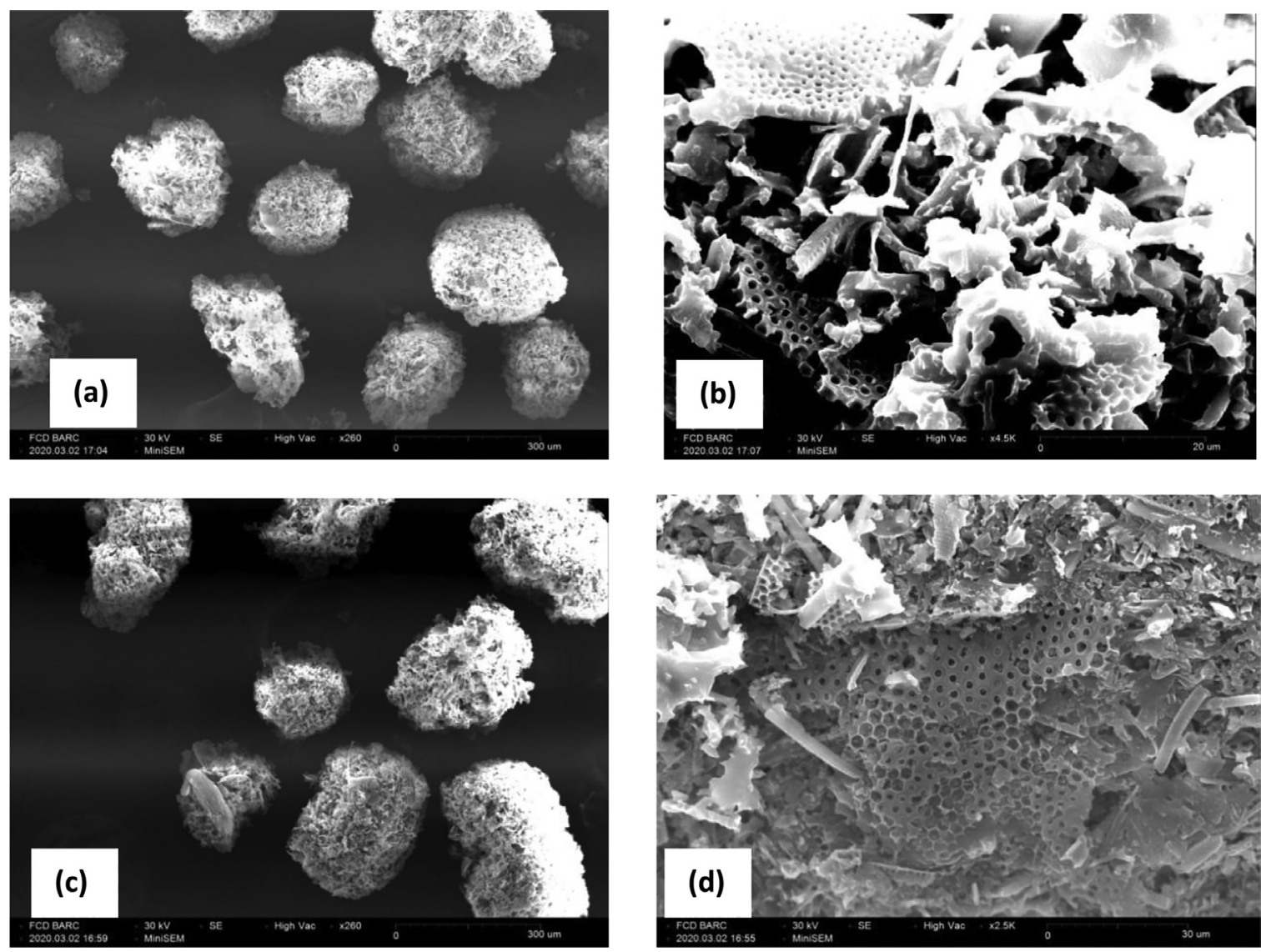

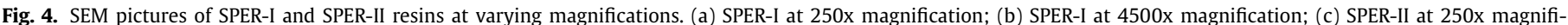
cation; (d) SPER-II at 2500x magnification.

Table 2

Comparative $\mathrm{Np}$ (IV) (or analogous actinide ion) uptake data using extraction chromatographic resins containing DGA-based or analogous extractants. Uptake studies were carried out at $3 \mathrm{M} \mathrm{HNO}_{3}$. Values inside parentheses are for Pu.

\begin{tabular}{lllll}
\hline Extractant in the SPER & Extractant loading & Support & $K_{\mathrm{d}}$ & Ref. \\
\hline Aliquat 336 & $15 \%$ & Chromosorb W & 320 & {$[20]$} \\
TODGA & $13 \%$ & Amberchrom $®$ CG-71C & $\sim 2500^{\mathrm{a}}$ & {$[21]$} \\
TODGA & $40 \%$ & Amberchrom ${ }^{\mathrm{a}}$ CG-71 & $\sim 1700^{\mathrm{a}}$ & {$[22]$} \\
TODGA & $47 \%$ & Chromosorb W & $5130^{\mathrm{b}}$ & {$[23]$} \\
C4DGA & $12 \%$ & Chromosorb W & $5305^{\mathrm{b}}$ & {$[24]$} \\
$\mathbf{L}_{\mathbf{I}}$ (C4DGA) & $8 \%$ & Chromosorb W & $47544(2321)^{\mathrm{b}}$ & This work \\
$\mathbf{L}_{\text {II }}$ (C4DGA) & $8 \%$ & Chromosorb W & $13724(1874)^{\mathrm{b}}$ & This work
\end{tabular}

a Data obtained for Th(IV).

b Data obtained for Pu(IV).

should increase with increasing nitric acid concentration. The results of the nitric acid concentration variation studies are presented in Fig. 6. All uptake studies were carried out at $\mathrm{HNO}_{3}$ concentrations $\geq 0.5 \mathrm{M}$ due to the possibility of hydrolysis at lower concentrations. It is interesting to note that the $K_{\mathrm{d}}$ values of $\mathrm{Np}$ (IV) are ca. 50,000 and 3100, respectively, with the SPER-I and SPERII at $0.5 \mathrm{M} \mathrm{HNO}_{3}$, making the former resin about 16 times more efficient. The $K_{\mathrm{d}}$ values show an increasing trend with increasing $\mathrm{HNO}_{3}$ concentration for SPER-II, a steeper increase in the range 0.5 - $3 \mathrm{M} \mathrm{HNO}_{3}$, followed by a significantly less steep rise thereafter. On the other hand, an almost flat profile is seen for SPER-I in the entire nitric acid concentration range investigated in this study.

\subsection{Uptake other actinide and fission product elements}

Though $\mathrm{Np}$ is one of the most important actinide elements, present in the high-level liquid wastes, there are also other ac- tinide elements such as Am, Pu and $\mathrm{U}$ and fission product elements such as rare earths and Cs (responsible for the high gamma ray dose to the personnel) in the acidic radioactive wastes. As shown in Table 3, while $\mathrm{Am}^{3+}, \mathrm{Eu}^{3+}$ (taken as a surrogate of the rare earth elements) and $\mathrm{Pu}^{4+}$ are extracted to a significant extent, though to a much lower extent than $\mathrm{Np}^{4+}, \mathrm{UO}_{2}{ }^{2+}$ is not quite extracted. The $K_{\mathrm{d}}$ value of ca. 5-10 for $\mathrm{UO}_{2}{ }^{2+}$ suggests that it cannot be held onto a column containing the resins. On the other hand, $\mathrm{Cs}(\mathrm{I})$ was not extracted to any extent $\left(K_{\mathrm{d}}<0.001\right)$. The uptake of the metal ions follows the trend: $\mathrm{Np}^{4+}>\mathrm{Eu}^{3+}>\mathrm{Am}^{3+}>\mathrm{Pu}^{4+}>>\mathrm{UO}_{2}{ }^{2+}$ $>\mathrm{Cs}^{+}$. The $\mathrm{K}_{\mathrm{d}}$ values of $\mathrm{Pu}(\mathrm{IV})$ are much lower than those reported for a previously studied resin containing another C4DGA ligand with n-octyl groups [27]. This is partly due to lower ligand loading in the present set of SPERs and also partly due to the fact that the C4DGA with n-octyl groups is a better extractant of metal ions. The poor uptake of $\mathrm{UO}_{2}{ }^{2+}$ and $\mathrm{Cs}^{+}$ions shows that, while treating radioactive wastes, these ions will not be taken up by both 
Table 3

Batch uptake data of different metal ions by the SPER-I and SPER-II resins at $3 \mathrm{M} \mathrm{HNO}_{3}$.

\begin{tabular}{lllllll}
\hline \multirow{2}{*}{ Resin } & \multicolumn{6}{l}{$K_{\mathrm{d}}$} \\
\cline { 2 - 6 } & $\mathrm{Np}(\mathrm{IV})$ & $\mathrm{Am}(\mathrm{III})$ & $\mathrm{Eu}(\mathrm{III})$ & $\mathrm{U}(\mathrm{VI})$ & $\mathrm{Pu}(\mathrm{IV})$ & $\mathrm{Cs}(\mathrm{I})$ \\
\hline SPER-I & $47544 \pm 2377$ & $16885 \pm 844$ & $25795 \pm 1240$ & $5.16 \pm 0.25$ & $2321 \pm 114$ & $<0.001$ \\
SPER-II & $13724 \pm 617$ & $12806 \pm 604$ & $15525 \pm 770$ & $9.03 \pm 0.45$ & $1874 \pm 93$ & $<0.001$ \\
\hline
\end{tabular}

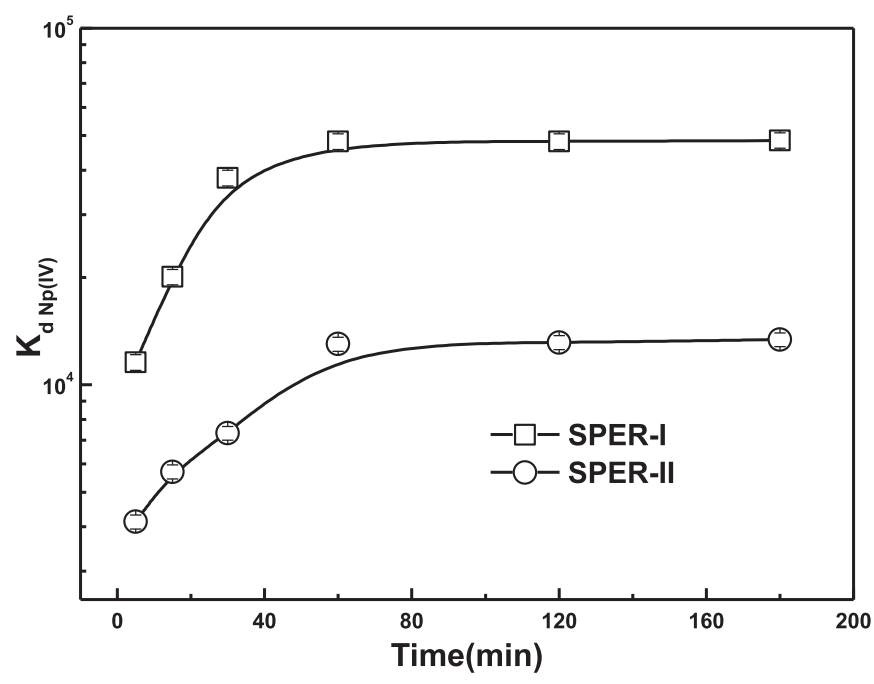

Fig. 5. Effect of equilibration time on the uptake of $\mathrm{Np}(\mathrm{IV})$ by the SPER-I and SPERII resins as measured by the $K_{\mathrm{d}}$ values from a feed containing $3 \mathrm{M} \mathrm{HNO}_{3}$.

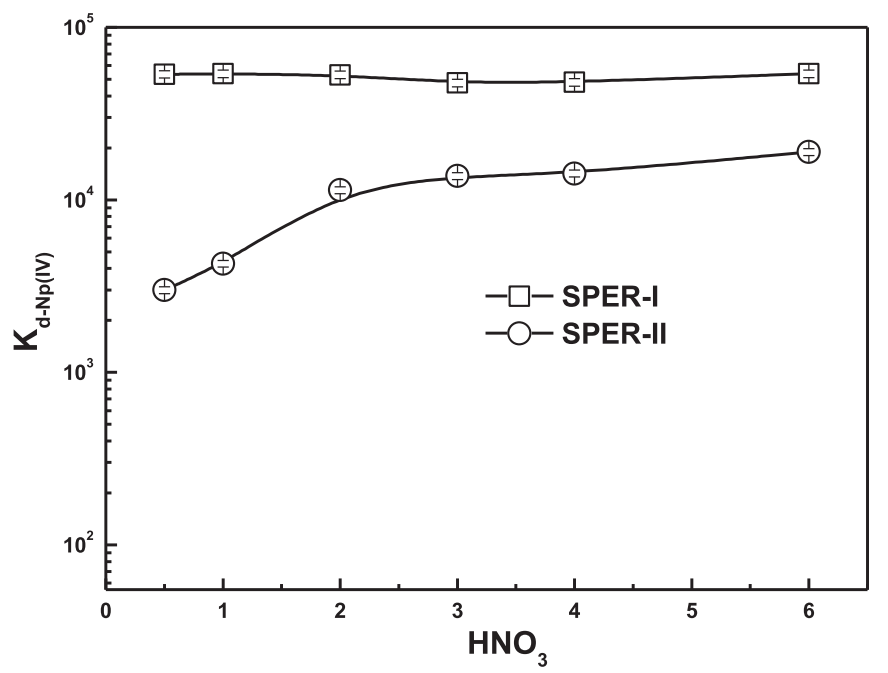

Fig. 6. Effect of the aqueous feed nitric acid concentration on the uptake of $\mathrm{Np}$ (IV) by the SPER-I and SPER-II resins as measured by the $K_{\mathrm{d}}$ values.

the SPERs. However, the separation of $\mathrm{Np}^{4+}, \mathrm{Pu}^{4+}$ and $\mathrm{Am}^{3+}$ is not possible unless their oxidation states are adjusted to their unextractable forms. This means that $\mathrm{Pu}$ and $\mathrm{Np}$ can be oxidized to the unextractable +5 or +6 oxidation states for their separation from $\mathrm{Am}^{3+}$, if all three are present together. Nevertheless, the uptake data shows that the resins hold promise for actinide ion uptake from acidic feeds such as nuclear wastes.

\subsection{Back extraction and reusability}

Back extraction of the loaded activity could be a measure of the recovery efficiency of the metal ion. In addition, it is also important to evaluate the efficacy of the recovered resin for subsequent
Table 4

Back extraction of the loaded ${ }^{239} \mathrm{~Np}$ (IV) using various stripping agents.

\begin{tabular}{|c|c|c|}
\hline Resin & Stripping solution & $\%$ Back extraction \\
\hline SPER-I & $0.5 \mathrm{M}$ Oxalic acid $+0.5 \mathrm{M} \mathrm{HNO}_{3}$ & 88.5 \\
\hline SPER-II & $0.5 \mathrm{M}$ Oxalic acid $+0.5 \mathrm{M} \mathrm{HNO}_{3}$ & 88.6 \\
\hline SPER-I & 0.5 M Oxalic acid & 80.3 \\
\hline SPER-II & 0.5 M Oxalic acid & 79.8 \\
\hline SPER-I & $0.5 \mathrm{M} \mathrm{HNO}_{3}$ & 14.5 \\
\hline SPER-II & $0.5 \mathrm{M} \mathrm{HNO}_{3}$ & 7.4 \\
\hline
\end{tabular}

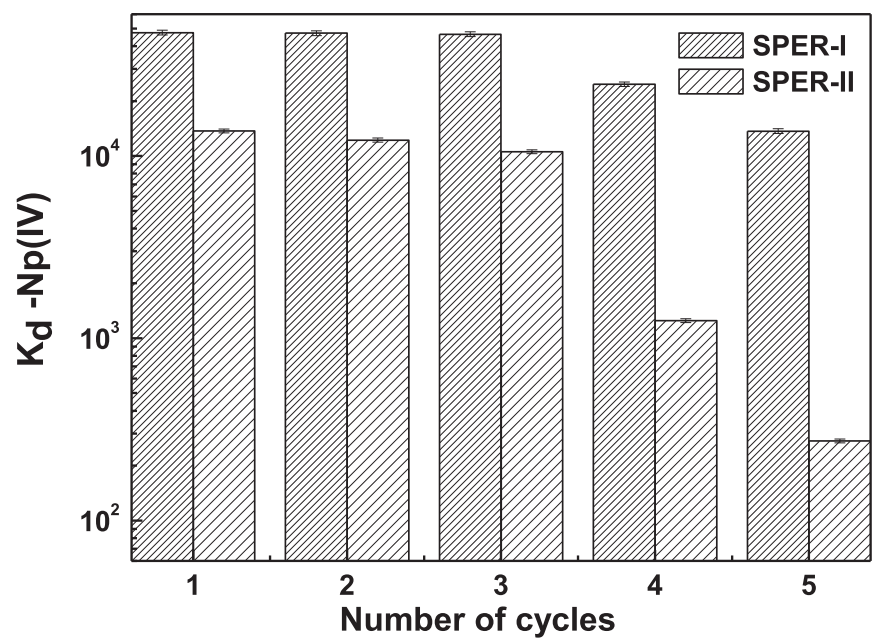

Fig. 7. Sorption and desorption of $\mathrm{Np}$ (IV) on the resins in five successive cycles to establish the stability of the resin.

reuse. For this purpose, batch experiments were carried out using ca. $20-30 \mathrm{mg}$ of the resins for back extracting the loaded ${ }^{239} \mathrm{~Np}$ activity. Three different stripping solutions were used, viz. $0.5 \mathrm{M}$ $\mathrm{HNO}_{3}$ (considering the $K_{\mathrm{d}}$ value of $\mathrm{Np}$ is low at low acid concentrations and hydrolysis possibility prevented to opt for lower acid concentration), $0.5 \mathrm{M}$ oxalic acid (used as a complexing agent for the tetravalent $\mathrm{Np}$ ) and a mixture of both, i.e., $0.5 \mathrm{M}$ oxalic acid $+0.5 \mathrm{M}$ nitric acid. The results are presented in Table 4 .

From Table 4 it is clear that the mixture of oxalic acid and nitric acid is the most efficient stripping agent with close to $90 \%$ back extraction with both the resins. In view of this, this mixture was used for the elution during the column studies (vide infra).

After the back-extraction studies, reusability studies were performed using the regenerated resin for another cycle of extraction and back extraction. Five such cycles of 'extraction - back extraction' were carried out for a fair assessment of the resin performance in long term use. The reusability graph is presented in Fig. 7, which suggests deterioration of the resins on contineous use. Both the SPER-I and SPER-II resins remain quite stable up to three repeat runs, after which the $K_{\mathrm{d}}$-values decrease. However, while the decrease in the $K_{\mathrm{d}}$ values for SPER-II was quite significant and the very low $K_{d}$ value (decreased from 13,724 on the first loading to 273 on the fifth loading) rendered the resin quite ineffective, this was not the case for SPER-I. Though a five-fold decrease in the $K_{\mathrm{d}}$ value was obtained after five successive runs, it was still $>1 \times 10^{4}$ suggesting that it can be quite useful for $\mathrm{Np}^{4+}$ ion up- 
take. The aqueous phase was filtered through a 0.2 micron syringe filter and the $K_{\mathrm{d}}$ values were measured again. As the $K_{\mathrm{d}}$ values were within $\pm 2 \%$, which is the error in the measurements, it appeared that the resin particles were not disintegrated during the batch uptake studies.

Finally, while evaluating the reusability of the resin materials, one needs to study the radiolytic degradation of the resin. Though our previous studies on solvent extraction using the n-propyl and isopentyl derivatives of the C4DGA ligands have shown marginal degradation, it was of interest to carry out similar studies using the SPERs. The resins were exposed to $300 \mathrm{kGy}$ gamma ray dose in a ${ }^{60} \mathrm{Co}$ irradiator with a dose rate of $4 \mathrm{kGy} /$ hour and the $K_{\mathrm{d}}$ values were determined under identical conditions to those used for the data presented in Table 2 . While the $K_{\mathrm{d}}$ value of $\mathrm{Np}$ (IV) marginally decreased for SPER-I from 47,544 to 46,588, the respective numbers were 13,724 and 13,218 for SPER-II suggesting almost no loss in the uptake efficiencies. As the SPERs find effective use in the pre-concentration and estimation of the radionuclides in lean effluents and environmental samples, it was not required to study the degradation at higher absorbed dose values.

\subsection{Sorption isotherms}

Though the binding of the actinide ions, sans $\mathrm{UO}_{2}{ }^{2+}$, was very impressive with both the resins SPER-I and SPER-II, it was of interest to understand the sorption isotherm to it may be conforming to. Usually, the uptake parameters such as $q_{\mathrm{t}}$, the metal ion uptake capacity at a given time, and the equilibrium metal ion uptake capacity $q_{\mathrm{e}}$, are needed as a function of the initial as well as the equilibrium concentration of the metal ion, for this purpose. In this context, the initial metal ion concentration is very important and should be much in excess to the amount of metal ion needed to saturate the available uptake sites in the resins. As ${ }^{239} \mathrm{~Np}$ was used as the radiotracer, which is carrier free, the feed solution was spiked for the sorption isotherm studies with a $\operatorname{Th}\left(\mathrm{NO}_{3}\right)_{4}$ solution considering the similar chemical properties of $\mathrm{Np}^{4+}$ and $\mathrm{Th}^{4+}$. Though $\mathrm{Th}^{4+}$ has somewhat higher ionic size as compared to that of $\mathrm{Np}^{4+}$, it was considered a suitable surrogate on account of the fact that it comes close to $\mathrm{Np}^{4+}$ in its chemical properties as compared to other possible surrogate tetra-valent ions such as $\mathrm{Zr}^{4+}$ and $\mathrm{Hf}^{4+}$ which have much smaller ionic radii (both ca. 0.8 $\AA$ ) [29] and hence, higher ionic potential as compared to $\mathrm{Np}^{4+}$. Furthermore, using a relatively large amount of $\mathrm{Np}$ (in the form of ${ }^{237} \mathrm{~Np}$ ) would require an elaborate facility for the alpha activity and hence, was not considered in this study. The equation for the
Langmuir adsorption isotherm is given as:

$$
\frac{C_{e q}}{q_{t}}=\frac{[1]}{b \cdot q_{\max }}+\frac{C_{e q}}{q_{\max }}
$$

where $C_{\text {eq }}$ and $q_{\max }$ are the equilibrium concentration of the metal ion and the maximum uptake capacity (which indicates the monolayer coverage of metal ions on the solid), respectively, while ' $b$ ' is the Langmuir constant. An aqueous feed containing $1 \mathrm{~g} / \mathrm{L}$ of Th and spiked with ${ }^{239} \mathrm{~Np}$ was used for these studies and the equilibrium sorption capacity was determined at varying metal ion concentrations in the aqueous feed solution. After fitting the results to the Langmuir model (Fig. 8a) straight-line plots were obtained with $\mathrm{R}^{2}$ values > 0.99 (Table 5) suggesting conformation to the monolayer model. The maximum uptake capacity was found to be $31.2 \pm 1.2$ and $25.6 \pm 1.1 \mathrm{mg}$ of the tetravalent actinide ion per $\mathrm{g}$ of SPEI1 and SPER-II, respectively. The $b$ values obtained from the fitting of the straight-line Langmuir plots (Table 5) can be expressed in terms of a dimensionless equilibrium constant, $R \mathrm{~L}$ (also known as the separation factor [30]) as per the following equation:

$R_{L}=1 /\left(1+b C_{0}\right)$

where $C_{o}$ is the initial concentration of the metal ion. Eq. (5) is used to evaluate the favourability of the Langmuir isotherm model [31]. The value of $R_{\mathrm{L}}$ can give an idea about the finer details of the uptake of the metal ion. While $R_{\mathrm{L}}>1$ represents unfavourable sorption, favourable sorption is given as $0<R_{\mathrm{L}}<1$ and an irreversible uptake is represented by $R_{\mathrm{L}}$ values equalling to zero. The value of $R_{\mathrm{L}}$ was calculated for a series of initial thorium concentrations and found to fall between 0 and 1 ( 0.132 for SPER-I and 0.095 for SPER-II), which confirms that the sorption of $\mathrm{Np}(\mathrm{IV})$ onto the SPER resins is favourable.

Next, the uptake data was fitted to the Freundlich isotherm model [32] which is represented by the following equation, which assumes multilayer sorption of the metal ions on the surface.

$\log q_{e q}=\log K_{f}+\frac{1}{n} \log C_{e q}$

The sorption data were fitted to the linearized Freundlich equation (Eq. 6) and the results are presented in Fig. 8b. As seen from the figure, the fittings are inferior to those seen for the Langmuir isotherm as concluded from the $\mathrm{R}^{2}$ values (Table 5), suggesting that the multilayer sorption phenomenon may be absent in the case of both the SPER-I and SPER-II resins. The sorption data were subsequently fitted to the D-R isotherm model [33] given by the following equation:

$\ln q_{\mathrm{t}}=\ln q_{\max }-\beta \varepsilon^{2}$

Table 5

Parameters calculated from the Langmuir, Freundlich, D-R and Temkin isotherm models for the sorption of $\mathrm{Cs}(\mathrm{I})$ on composite beads; Aqueous phase: $\mathrm{pH} 3$.

\begin{tabular}{llll}
\hline Isotherms & Parameters & Values at $25^{\circ} \mathrm{C}$ & \\
\cline { 3 - 4 } & & SPER-I & SPER-II \\
\hline Langmuir & $\mathrm{b}(\mathrm{mL} / \mathrm{mg})$ & $6.6 \times 10^{-3}$ & $9.5 \times 10^{-3}$ \\
& $\mathrm{q}_{\max }(\mathrm{mg} / \mathrm{g})$ & $31.2 \pm 1.2(30.3 \pm 1.3)^{\mathrm{a}}$ & $25.6 \pm 1.1(24.5 \pm 1.2)^{\mathrm{a}}$ \\
& $\mathrm{R}^{2}$ & 0.9927 & 0.9939 \\
\hline Freundlich & $\mathrm{K}_{\mathrm{f}}(\mathrm{mg} / \mathrm{g})$ & $0.521 \pm 0.081$ & $-0.669 \pm 0.134$ \\
& $1 / \mathrm{n}$ & $0.32 \pm 0.02$ & $0.76 \pm 0.03$ \\
& $\mathrm{R}^{2}$ & 0.9756 & 0.9929 \\
\hline \multirow{2}{*}{$\mathrm{D}-\mathrm{R}$} & $q_{\max }(\mathrm{mmol} / \mathrm{g})$ & $0.222 \pm 0.010$ & $0.184 \pm 0.018$ \\
& $\mathrm{E}(\mathrm{kJ} / \mathrm{mole})$ & $12.04 \pm 0.62$ & $12.91 \pm 0.71$ \\
& $\mathrm{R}^{2}$ & 0.999 & 0.996 \\
\hline Temkin & $\mathrm{A}_{\mathrm{T}}$ & $0.082 \pm 0.005$ & $0.048 \pm 0.003$ \\
& $\mathrm{R}^{2}$ & 0.972 & 0.949 \\
\hline
\end{tabular}

a Values in parentheses refer to the experimental values. 

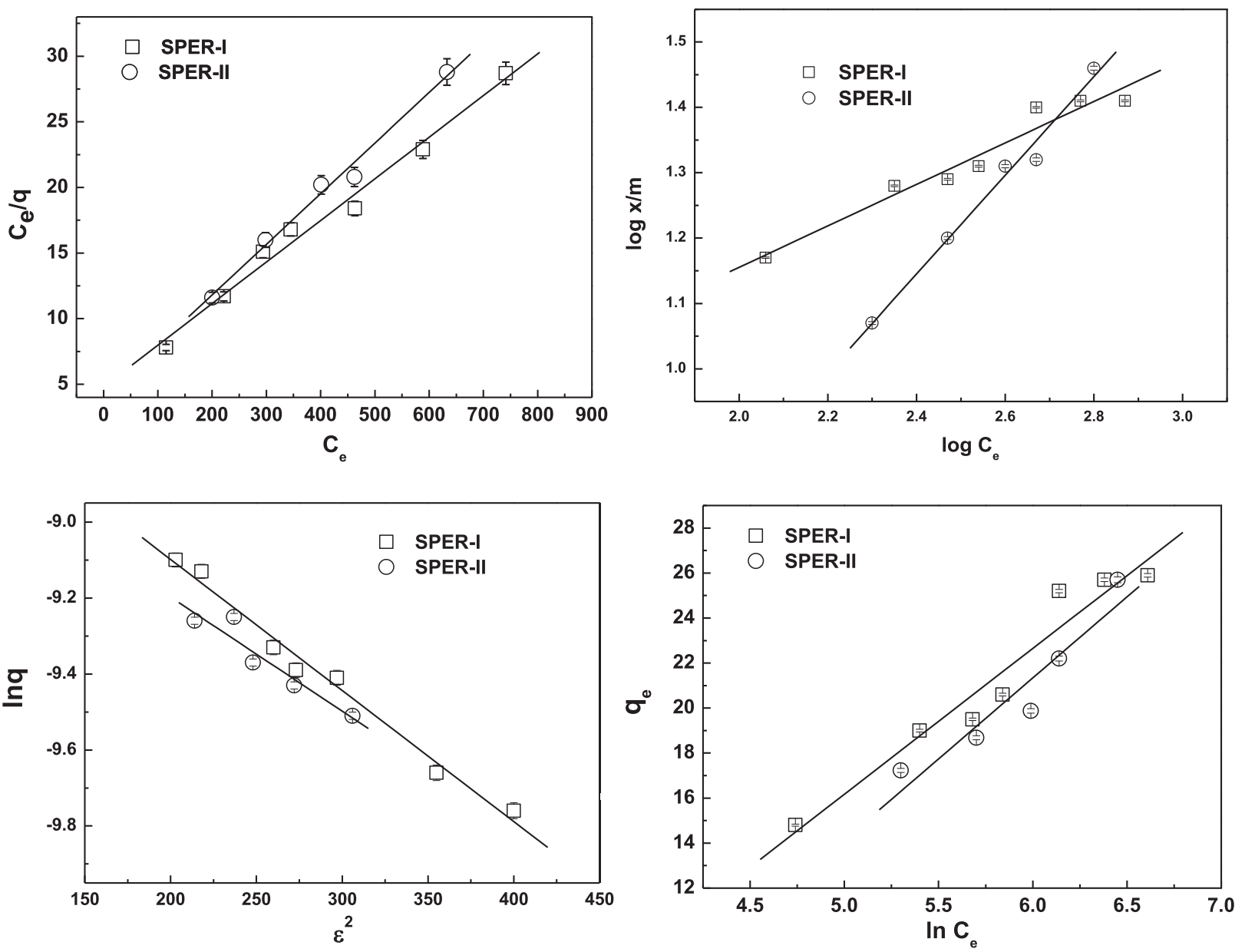

Fig. 8. Uptake data fitted to the linearized forms of (a) Langmuir, (b) Freundlich, (c) D-R and (d) Temkin sorption isotherms.

where $\beta$ and $\varepsilon$ represent the D-R constant and the Polanyi potential, respectively. The fitting to the above equation was found to be reasonably good (Fig. 8c) with a $R^{2}$ value of 0.999 and 0.996 , respectively, for SPER-I and SPER-II. The parameters of the linear fitting of the D-R equation are also listed in Table 5. The quantity $\beta$ can be correlated to the mean sorption energy (E), the free energy needed to transfer one mole of metal ions from infinity to the surface of the sorbent [34], as given by the following equation:

$E=1 / \sqrt{-2 \beta}$

The value of $E$ can throw light on the sorption mechanism, i.e., whether it is chemisorption or physisorption [35]. A value of $E>8$ $\mathrm{kJ} / \mathrm{mol}$ signifies to a chemisorption process, whereas a value $<8$ $\mathrm{kJ} / \mathrm{mol}$ points to a physisorption process. For the sorption of the tetravalent actinide ions the values of $E$ for SPER-I and SPER-II were found to be $12.04 \pm 0.61 \mathrm{~kJ} / \mathrm{mol}$ and $12.91 \pm 0.70 \mathrm{~kJ} / \mathrm{mol}$, respectively, (Table 5) indicating that the sorption takes place via chemical interactions.

Apart from the Langmuir and the D-R isotherm models, which fitted well with the sorption data obtained, an attempt was made to model to the Temkin isotherm as given by Eq. (9):

$q_{e}=\mathrm{B} \ln A_{T}+\mathrm{B} \ln C_{e}$

where $A_{T}$ is the Temkin constant. The Temkin isotherm model takes into account the effects of indirect adsorbate/adsorbate interactions on the adsorption process. The Temkin isotherm model is based on a multi-layer phenomenon which suggests that the heat of sorption of all the molecules in the layer would decrease linearly with coverage. The sorption data were fitted to the Temkin isotherm model (Fig. 8d) and the fit parameters are included in Table 5. As seen from the figure, the fitting was not good and hence, the fitting parameters were not used for the interpretation.

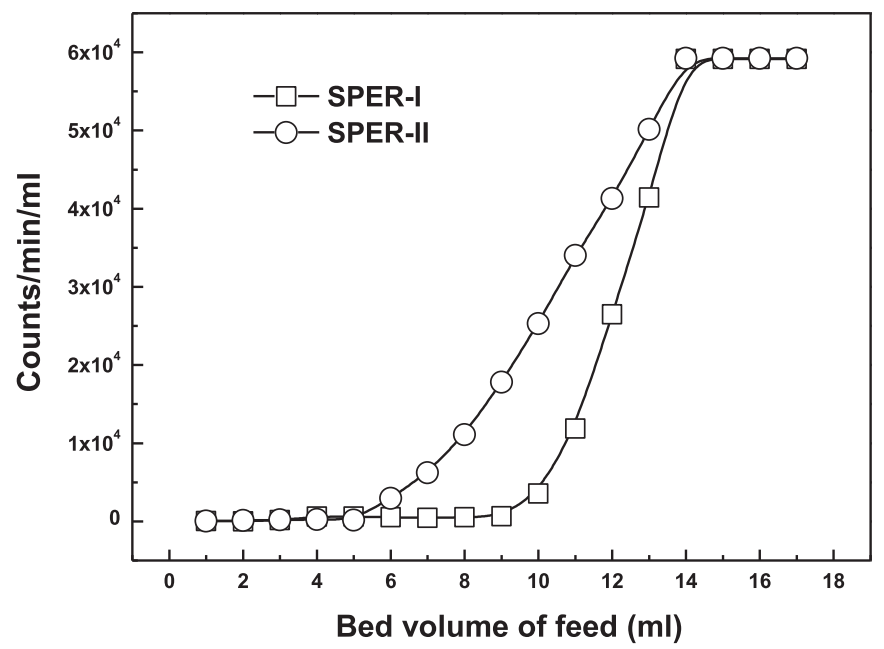

Fig. 9. Breakthrough profiles for the $\mathrm{Np}(\mathrm{IV})$ uptake columns containing SPER-I and SPER-II resins (Table 5). Feed contained ${ }^{239} \mathrm{~Np}$ tracer spiked solution of $3 \mathrm{M} \mathrm{HNO}_{3}$ containing $1 \mathrm{~g} / \mathrm{L}$ Th. 


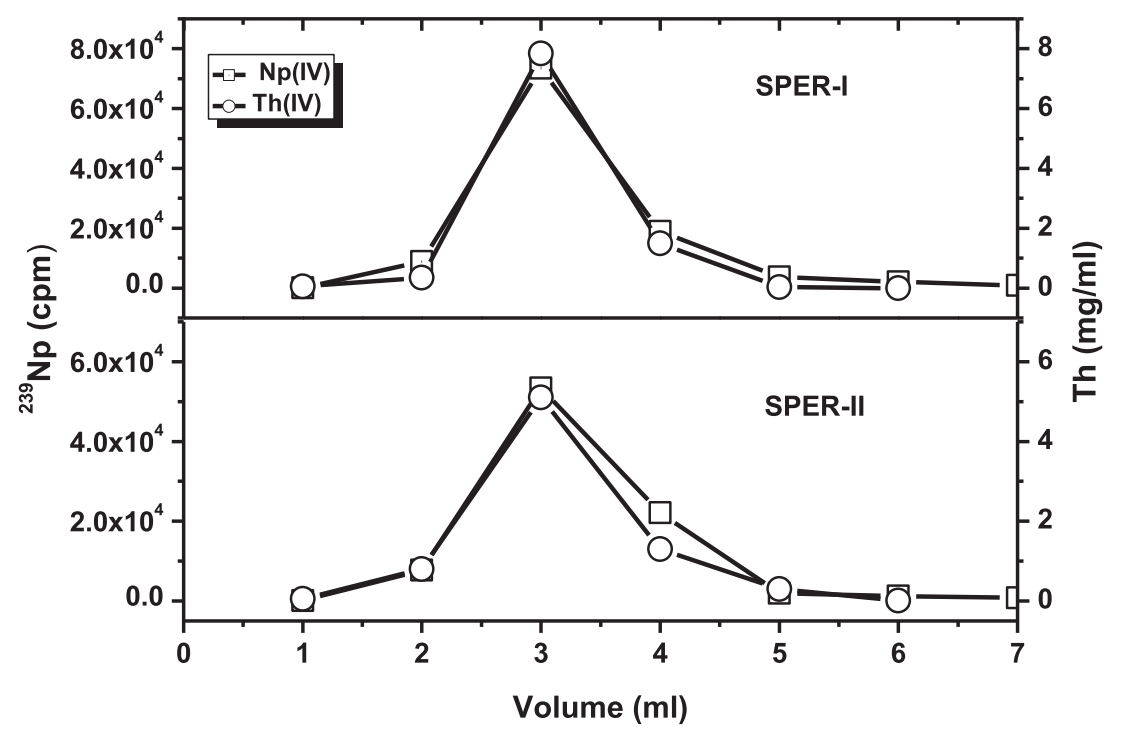

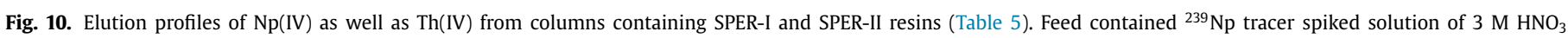
containing $1 \mathrm{~g} / \mathrm{L}$ Th.

\subsection{Column studies}

The batch uptake data (Table 2) being quite promising, column studies were carried out using a glass column whose parameters are defined in Table 1 . The column was conditioned by passing about $10 \mathrm{~mL}$ of $3 \mathrm{M} \mathrm{HNO}_{3}$. Subsequently, the feed solution containing $1 \mathrm{~g} / \mathrm{L}$ thorium nitrate in $3 \mathrm{M} \mathrm{HNO}_{3}$ and spiked with ${ }^{239} \mathrm{~Np}$ radiotracer (ca. $1000 \mathrm{~Bq}$ per $\mathrm{mL}$ ) was passed through the column and the effluent solution was counted for obtaining the breakthrough curves. As seen from Fig. 9, the SPER-I based column has a higher breakthrough volume $(9 \mathrm{~mL})$ as compared to the column containing the SPER-II resin, which is in line with their batch uptake efficiencies. These data suggest that a larger amount of the $\mathrm{Np}$ (IV) can be loaded onto the column containing SPER-I than onto the SPER-II column. The elution of the loaded actinide ion was carried out using a solution of $0.5 \mathrm{M}$ oxalic acid $+0.5 \mathrm{M}$ nitric acid as used in the back extraction studies (vide supra). Surprisingly, about $5 \mathrm{~mL}$ of the eluent was sufficient to elute out the loaded metal ion from the column (Fig. 10). A closer look to the figure suggests that the area under the elution curve for the SPER-I resin is significantly larger than that of the SPER-II resin, which is due to the higher amount of loaded metal ion on the former column. The same eluted fractions were subsequently used for the spectrophotometric assay of Th(IV) using Arsenazo III as the chromogenic agent as reported in a previous paper [22]. The elution profiles of $\mathrm{Th}$ (IV) matched very well with those obtained for $\mathrm{Np}$ (IV) supporting the choice of $\mathrm{Th}(\mathrm{IV})$ as a surrogate of $\mathrm{Np}(\mathrm{IV})$.

\section{Conclusions}

From the extraction chromatography studies involving the two SPERs, containing the C4DGA extractants, it is clear that the uptake of $\mathrm{Np}(\mathrm{IV})$ ions is significantly large for both the resins, the $K_{\mathrm{d}}$ values being $>3$ times larger for SPER-I than that with SPER-II. With only $8 \%$ loading of the two C4DGA extractants, the $K_{\mathrm{d}}$ results are much better for both the SPER-I and SPER-II resins as compared to the previously reported TODGA resins have a significantly higher extractant loading (in the range of 13 - 47\%) with other tetravalent actinide ions such as Th(IV) and $\mathrm{Pu}(\mathrm{IV})$. A previously reported Aliquat 336 based resin displayed much lower (about 2 orders) $K_{\mathrm{d}}$ values, suggesting that the present set of resins are the best reported for $\mathrm{Np}$ (IV) uptake so far. The very high uptake of the metal ion suggests that the SPERs can be used for the separation of $\mathrm{Np}$ from acidic feeds such as those encountered in radioactive wastes.

The batch uptake data conformed to the Langmuir sorption isotherm suggesting a monolayer adsorption mechanism and point to chemisorption where the uptake is followed by a chemical reaction. The column studies indicate facile loading and elution with both the resins, though the SPER-I resin-based column showed a significantly higher efficiency. All these above results based on the batch as well column studies indicate that the C4DGA-based resins can be used for the uptake of $\mathrm{Np}$ (IV) ions from feeds similar to the high level liquid nuclear waste (HLLW) and hence, show promise for application to radioactive waste remediation.

\section{Declaration of Competing Interest}

The authors have no conflict of interest to declare.

\section{CRediT authorship contribution statement}

Rajesh B. Gujar: Investigation, Formal analysis. Prasanta K. Mohapatra: Conceptualization, Methodology. Mudassir Iqbal: Software. Jurriaan Huskens: Supervision. Willem Verboom: Methodology.

\section{Acknowledgement}

The authors (RBG and PKM) thank Dr. P.K. Pujari, Head, Radiochemistry Division, Bhabha Atomic Research Centre for his constant encouragement.

\section{References}

[1] Z. Yoshida, S.G. Johnson, T. Kimura, J.R. Krsul, in: Actinide and Transactinide Elements, L.R. Morss, N.M. Edelstein, J. Fuger, J.J. Katz, (Eds.), Springer, 2006, Vol. 2, Ch. 6.

[2] C. Madic, M.J. Hudson, J.O. Liljenzin, J.-P. Glatz, R. Nannicini, A. Facchini, Z. Kolarik, Z.R. Odoj, New Partitioning Techniques for Minor Actinides, European Commission, Luxembourg, 2000 EUR 19149.

[3] S.A. Ansari, P. Pathak, P.K. Mohapatra, V.K. Manchanda, Aqueous partitioning of minor actinides by different processes, Sep. Purif. Rev. 40 (2011) 43-76.

[4] J.N. Mathur, M.S. Murali, K.L. Nash, Actinide partitioning - A review, Solvent Extr. Ion Exch. 19 (2001) 357-390.

[5] J.W. Boldeman, Accelerator driven nuclear, energy systems, Australian Academy of Technological Sciences and Engineering Symposium, Energy for Ever - Technological Challenges of Sustainable Growth, Future nuclear energy systems: Generating electricity, burning wastes, Viktor Arkhipov, IAEA Bulletin 39 (1997) 30-33. 
[6] J.C. Hindman, L.B. Magnusson, T.J. LaChapelle, The oxidation states of neptunium in aqueous solutions, J. Am. Chem. Soc. 71 (1949) 687-693.

[7] G.A. Burney, R.M. Harbour, Radiochemistry of neptunium (1974) 24 Report No. NAS-NS-3060.

[8] S.A. Ansari, P.N. Pathak, P.K. Mohapatra, V.K. Manchanda, Chemistry of diglycolamides: Promising extractants for actinide partitioning, Chem. Rev. 112 (2012) 1751-1772.

[9] L. Wu, Y. Fang, Y. Jia, Y. Yang, J. Liao, N. Liu, X. Yang, W. Feng, J. Ming, L. Yuan, Pillar[5] arene-based diglycolamides for highly efficient separation of americium(III) and europium(III), Dalton Trans 43 (2014) 3835-3838.

[10] P.K. Mohapatra, A. Sengupta, M. Iqbal, J. Huskens, W. Verboom, Highly efficient diglycolamide based Task-Specific Ionic Liquids: Synthesis, unusual extraction behaviour, irradiation, and fluorescence studies, Chem. Eur. J. 19 (2013) 3230-3238.

[11] Z. Zhu, Y. Sasaki, H. Suzuki, S. Suzuki, T. Kimura, Cumulative study on solvent extraction of elements by $N, N, N^{\prime}, N^{\prime}$-tetraoctyl-3-oxapentanediamide (TODGA) from nitric acid into n-dodecane, Anal. Chim. Acta 527 (2004) 163-168.

[12] R.B. Gujar, G.B. Dhekane, P.K. Mohapatra, Liquid-liquid extraction of $\mathrm{Np}^{4+}$ and $\mathrm{Pu}^{4+}$ using several tetra-alkyl substituted diglycolamides, Radiochim. Acta 101 (2013) 719-724

[13] M. Iqbal, P.K. Mohapatra, S.A. Ansari, J. Huskens, W. Verboom, Preorganization of diglycolamides on the calix[4]arene platform and its effect on the extraction of $\mathrm{Am}(\mathrm{III}) / \mathrm{Eu}(\mathrm{III})$, Tetrahedron 68 (2012) 7840-7847.

[14] P.K. Mohapatra, M. Iqbal, D.R. Raut, W. Verboom, J Huskens, S.V. Godbole, Complexation of novel diglycolamide functionalized calix[4]arenes: Unusual extraction behaviour, transport, and fluorescence studies, Dalton Trans 41 (2012) 360-363.

[[15]] R.B. Gujar, P.K. Verma, P.K. Mohapatra, M. Iqbal, J. Huskens, W. Verboom, Extraction of tetra- and hexavalent actinide ions from nitric acid solutions using some diglycolamide functionalized calix[4]arenes, Radiochim. Acta 109 (2021) $167-176$.

[16] O.B. Mokhodoeva, G.V. Myasoedova, E.A. Zakharchenko, E.A. Solid-phase extractants for radionuclide pre-concentration and separation. New possibilities, Radiochemistry 53 (2011) 35-43.

[17] I. Akaza, in: Extraction Chromatography, T. Braun, G. Ghersini, (Eds.), Elsevier, NY, 1975, p. 17.

[18] S. Risticevic, V.H. Niri, D. Vuckovic, J. Pawliszyn, Recent developments in solid-phase micro-extraction, Anal. Bioanal. Chem. 393 (2001) 781-795.

[19] S.A. Ansari, P.K. Mohapatra, A review on solid phase extraction of actinides and lanthanides with amide based extractants, J. Chromatogr. A 1499 (2017) $1-20$.

[20] P.K. Mohapatra, P.B. Ruikar, V.K. Manchanda, Separation of neptunium and plutonium from acidic medium using 3-phenyl-4-benzoyl-5-isoxazolone, Radiochim. Acta 90 (2002) 323-327.

[21] P.K. Mohapatra, S. Sriram, V.K. Manchanda, L.P. Badheka, Uptake of metal ions by extraction chromatography using dimethyl dibutyl tetrade- cyl-1,3-malonamide (DMDBTDMA) as the stationary phase, Sep. Sci. Technol. 35 (2000) 39-55.

[22] P. Thakur R. Veeraraghavan, P.K Mohapatra V.K Manchanda K.C. Dash, Extraction of ternary complexes of thorium(IV) with 3-phenyl-4-benzoyl-5-isoxazolone and neutral donors from nitric acid medium, Talanta 43 (1996) 1305-1312.

[23] B.N. Mahanty, A. Bhattacharyya, P.K. Mohapatra, Separation of neptunium(IV) from actinides by solid phase extraction using a resin containing Aliquat 336, J. Chromatogr. A 1564 (2018) 94-101.

[24] K. Van Hecke, G. Modolo, Separation of actinides from Low Level Liquid Wastes (LLLW) by extraction chromatography using novel DMDOHEMA and TODGA impregnated resins, J. Radioanal. Nucl. Chem. 261 (2004) 269-275.

[25] E.P. Horwitz, D.R. McAlister, A.H. Bond, R.E. Barrans, Novel extraction of chromatographic resins based on tetraalkyldiglycolamides: characterization and potential applications, Solvent Extr. Ion Exch. 23 (2005) 319-344.

[26] S.A. Ansari, P.N. Pathak, M. Hosain, A.K. Prasad, V.S. Parmar, V.K. Manchanda, Extraction chromatographic studies of metal ions using $N, N, N^{\prime}, N^{\prime}$-tetraoctyl diglycolamide as the stationary phase, Talanta 68 (2006) 1273-1280.

[27] S.A. Ansari, P.K. Mohapatra, M. Iqbal, J. Huskens, W. Verboom, Two novel extraction chromatography resins containing multiple diglycolamide-functionalized ligands: Preparation, characterization and actinide uptake properties, J. Chromatogr. A 1334 (2014) 79-86.

[28] Y. Sasaki, Y. Sugo, S. Suzuki, S. Tachimori, The novel extractants, diglycolamides for the extraction of lanthanides and actinides in $\mathrm{HNO}_{3}$ - n-dodecane system, Solvent Extr. Ion Exch. 19 (2001) 91-103.

[29] R.D. Shannon, Revised Effective Ionic Radii and Systematic Studies of Interatomie Distances in Halides and Chaleogenides, Acta Crystal. A32 (1976) $751-767$.

[30] N. Ayawei, A.N. Ebelegi, D. Wankasi, Modelling and interpretation of adsorption isotherms, J. Chem. (2017) 11 VolumeArticle ID 3039817pages, doi:10. $1155 / 2017 / 3039817$.

[31] I. Langmuir, The constitution and fundamental properties of solids and liquids, J. Am. Chem. Soc. 38 (1916) 2221-2295.

[32] H.M.F. Freundlich, Über die Adsorption in Lösungen, Z. Physik. Chemie 57A (1906) 385-470.

[33] M.M. Dubinin, The potential theory of adsorption of gases and vapors for adsorbents with energetically non-uniform surfaces, Chem. Rev. 60 (1960) 235-241.

[34] A. El Nemr, Potential of pomegranate husk carbon for $\mathrm{Cr}(\mathrm{VI})$ removal from wastewater: Kinetic and isotherm studies, J. Hazard. Mat. 161 (2009) 132-141.

[35] S. Kundu, A.K. Gupta, Investigation on the adsorption efficiency of iron oxide coated cement (IOCC) towards $\mathrm{As}(\mathrm{V})$-kinetics, equilibrium and thermodynamic studies, Colloids Surf. A 273 (2006) 121-128. 